\title{
Ex libris tradicionales, oralidad y ladrones de libros
}

\section{Traditional Ex Libris, Orality and Book Thieves*}

\author{
María Teresa SAGARzAzU YeREGUI \\ (Biblioteca del Conservatorio de Música Jesús Guridi de Vitoria-Gasteiz) \\ 010131bi@hezkuntza.net \\ ORCID ID: 0000-0003-2497-5286
}

\begin{abstract}
The elaboration process of the bibliographical records of collections of printed music is full of surprises. This note describes the discovery of a curious ex libris or bookplate contained in a nineteenth-century violin method. It is a type of traditional ex libris, in Spain and Latin America, which contains the classic, popular formula with the incipit «si este libro se perdiera...» («if this book should get lost...»). These simple ex libris, although they are, mostly transmitted in written form, present stylistic characteristics and modes of evolution, which are typical of oral transmission.
\end{abstract}

KEYWORDS: traditional ex libris, bibliographic description, printed music, bibliographic record, orality
RESUMEN: El proceso de elaboración de los registros bibliográficos de los fondos de música impresa está lleno de sorpresas. En esta nota se describe el hallazgo de un curioso ex libris contenido en un método de violín del siglo XIX. Se trata de un tipo de ex libris tradicional en España e Hispanoamérica que contiene la fórmula clásica popular con el íncipit «si este libro se perdiera...». Estos sencillos ex libris, aunque son fundamentalmente textos de transmisión escrita, presentan características estilísticas y modos de evolución propios de la transmisión oral.

PALABRAS-CLAVE: ex libris tradicional, descripción bibliográfica, música impresa, registro bibliográfico, oralidad

El hallazgo de un curioso ex libris, acompañado de anotaciones manuscritas, caricaturas, firmas, fechas y referencias históricas, en un ejemplar de un método de violín del siglo XIX, que se encuentra en la biblioteca del Conservatorio Jesús Guridi de VitoriaGasteiz, nos recuerda que cada ejemplar del que se recoge un registro bibliográfico puede estar lleno de datos importantes, a veces no muy evidentes. Es por tanto esencial recoger de manera exhaustiva la información contenida en los materiales bibliográficos, analizando tanto la propia música o texto contenidos en ellos como lo relacionado con el diseño de cubiertas y portadas, la publicidad, las marcas y sellos de propiedad, el número de plancha y editor, la encuadernación, signaturas antiguas, imprentas, distribuidores y puntos de venta, precios..., considerando, en definitiva, el documento como un todo (véase Iglesias Martínez et al., 2008: 28).

En los fondos antiguos de las bibliotecas se pueden descubrir datos de interés musicológico, filológico o histórico que obligan a un examen muy minucioso. Los

\footnotetext{
* Agradezco su orientación al profesor José Manuel Pedrosa.
} 
ejemplares están llenos de vida, nos cuentan su historia, quiénes fueron sus propietarios, cómo y cuándo formaron parte de la biblioteca, cuál fue su uso... Como dice Julián Martín Abad, maestro en incunables y manuscritos de la Biblioteca Nacional de España, «la historia del conocimiento de las ediciones y la del control de los ejemplares está llena de sorpresas, de fantasmas de vida (bibliográfica) prolongada y a veces tortuosa» (Martín Abad, 2004: 14).

El ejemplar que nos ocupa es un método de estudio de violín, titulado 10 estudios melódicos y progresivos para violín con acompañamiento de un $2^{\circ}$ violín ad libitum ${ }^{1}$, de Jean-Delphin Alard (1815-1888), violinista francés, compositor y profesor de violín en el Conservatorio de París, desde 1843 hasta 1875, donde tuvo a Pablo Sarasate (1844-1908) entre sus alumnos. Tanto esta obra ${ }^{2}$ como su más conocido método, Escuela de violín ${ }^{3}$, se utilizaron en muchos conservatorios europeos a mediados y finales del siglo XIX.

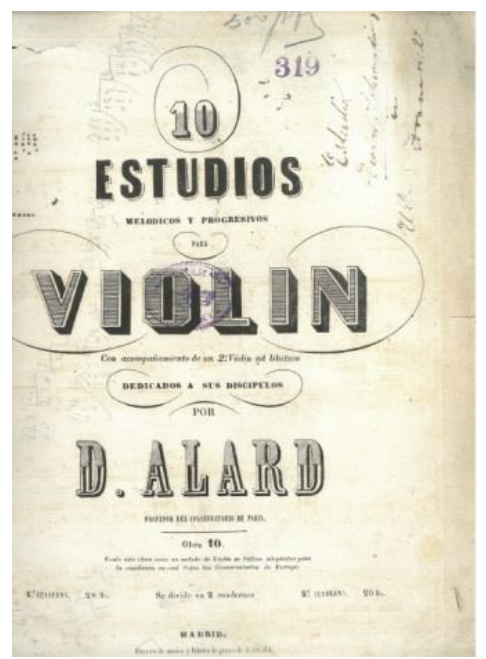

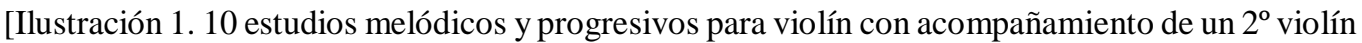
ad libitum, de Jean-Delphin Alard.]

${ }^{1}$ Descripción bibliográfica del ejemplar según las normas ISBD (PM) (Descripción Bibliográfica Internacional Normalizada para Música Impresa):

ALARD, Delphin (1815-1888)

[Études mélodiques et progressives. Español]

10 estudios melódicos y progresivos para violín con acompañamiento de un $2^{\circ}$ violín ad libitum, ler y $2^{\circ}$ cuaderno [Música impresa] / por D. Alard profesor del Conservatorio de París. - Madrid : B. Eslava, [1857-1882]

[38 p.] ; $34 \mathrm{~cm}$.

Fecha de publicación basada en La edición musical española hasta 1936, 1995. - Ded.: «Dedicados a sus alumnos». - Cada cuaderno incluye su propia secuencia de paginación. - En hoja de guarda anterior caricaturas y anotación manuscrita a tinta en letra cursiva en el lateral inferior: «Sirve para el uso de Teodoro Achaerandio en Vitoria». - En el verso de última hoja ex libris manuscrito que se lee en sentido transversal

N. pl.: B $4512 \mathrm{E}$

Violín - Estudios

${ }^{2} 10$ études mélodiques et progressives pour le violon avec accompagnement d'un second violon, ad libit., op. 10, París, Georges Schonenberger, 1843. Disponible en el portal digital Gallica:

<https://gallica.bnf.fr/ark:/12148/bpt6k1162350m.image> [Consultado el 30-04-2019].

${ }^{3}$ École du violon: méthode complète et progressive à l'usage du Conservatoire, París, Georges Schonenberger, 1844. Disponible en el portal digital Gallica:

<https://gallica.bnf.fr/ark:/12148/bpt6k1165754k.image> [Consultado el 30-04-2019]. 
Por la nota manuscrita «Sirve para el uso de Teodoro Achaerandio en Vitoria» en guarda anterior sabemos a quién perteneció este ejemplar ${ }^{4}$. Conocemos su precio (28 reales) y sabemos, además, que el propietario del método vivió la convulsa historia de la España del siglo XIX, ya que en el ejemplar aparecen referencias, en forma de caricaturas, a la Primera República Española (1873-74) y al reinado de Amadeo I de Saboya, rey de España entre 1871 y 1873. Las iniciales y el número de plancha utilizados (B 4512 E) nos informan de que fue editado en Madrid por el «Almacén de música y fábrica de pianos» de Bonifacio Eslava ${ }^{5}$ entre 1857 y 1882 (Gosálvez Lara, 1995: 153156).

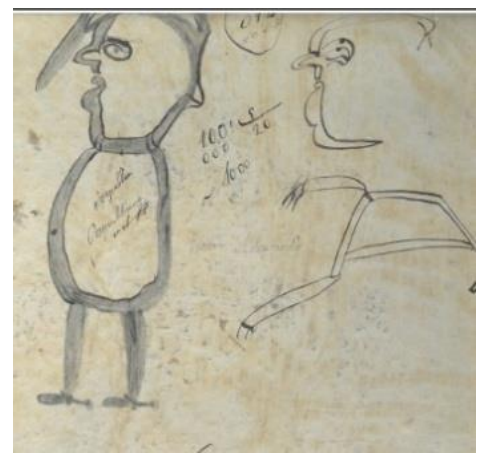

[Ilustración 2. Caricaturas con texto manuscrito: «república, republicanos».]

Sin embargo, uno de los aspectos más curiosos es el ex libris manuscrito encontrado en el método, que dice literalmente así:

Si este libro se perdiera como suele suceder suplico al que lo allare que me losepa volver que no es de cura ni de fraile ni tampoco de marqués que es de un pobre estudiante ${ }^{6}$ que no tiene que comer, si quiere saber mi nombre aquí abajo se lo pondre si no se le dará cuatro cuartos para que compre un cordel y al salir de la tienda se aorque con el.

\footnotetext{
${ }^{4}$ Véase Actas de bautismo del Archivo Histórico Diocesano de Vitoria: Teodoro Achaerandio Álvarez de Gamiz (ID: 84340 / 26-03-1858).

${ }^{5}$ Bonifacio Eslava, sobrino del compositor Hilarión Eslava, editó durante la segunda parte del s. XIX gran cantidad de métodos didácticos, partituras de música religiosa para órgano y obras para piano, participando además en la Exposición Universal celebrada en París en 1867, donde obtuvo la medalla de plata por sus ediciones. Véase la memoria oficial publicada por el musicólogo M. Fetis, presidente del jurado internacional de la Exposición Universal de 1867, en la Revista y Gaceta Musical, 14, 06-04, 1868, pp. 1-2. Disponible en la Biblioteca Digital Hispánica:

http://hemerotecadigital.bne.es/issue.vm?id=0003787433\&page=1\&search=revista+y+gaceta+musical +fet\%C3\%ADs\&lang=es [Consultado el 30-04-2019].

${ }^{6}$ Túmburus (1912) cita una variante similar: «... no es de cura ni de monje, / ni tampoco de mujer, / sino de un pobre estudiante...».
} 


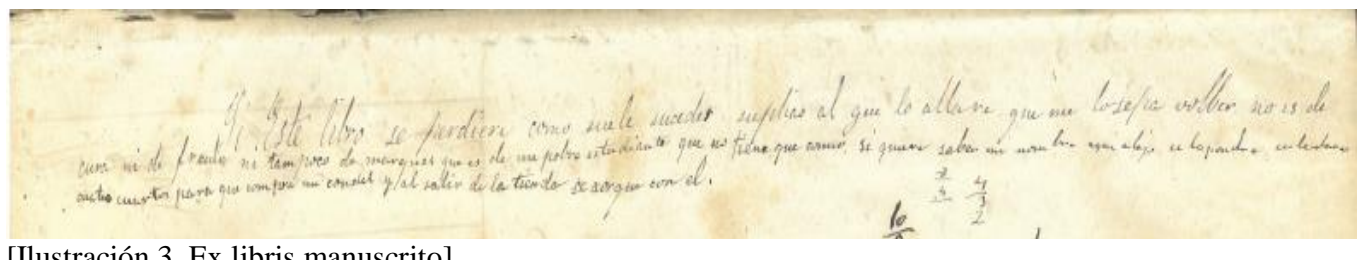

[Ilustración 3. Ex libris manuscrito]

Si bien es relativamente habitual encontrar exlibris manuscritos tradicionales en los ejemplares de los fondos históricos de las bibliotecas, no lo es tanto, como señala el profesor José Manuel Pedrosa en su artículo "“Si este libro se perdiera": geografía e historia de un ex-libris tradicional», encontrar en España ejemplos en los que aparezca la amenaza de la horca como medida coercitiva frente al robo de libros.

A la vista de todos estos textos, no puede menos que llamar la atención el que tanto en Portugal como en Francia e Italia hayan alcanzado cierto arraigo los ex-libris que amenazan con ahorcar a los ladrones de libros, motivo que no me ha sido posible localizar en España, o que por lo menos no figura entre los más característicos y conocidos de la tradición española. No tendría nada de extraño, en cualquier caso, que también en nuestro ámbito se hubieran conocido, al menos en tiempos pasados, textos que constituirían el lógico eslabón de unión de todas estas tradiciones, y que acaso algún día saldrán a la luz (Pedrosa, 2000: 123-124).

Desde la Edad Media existen innumerables ejemplos de ex libris manuscritos que pretenden disuadir a los ladrones de robar libros mediante variantes de la fórmula latina hic liber est meus (este libro es mío) ${ }^{7}$. Además, los bibliotecarios y los amanuenses medievales solían añadir en los libros maldiciones dirigidas a aquellos que no devolvían o dañaban los libros prestados, o que los robaban de sus bibliotecas. Estas maldiciones hacían referencia bien al castigo físico, bien a la condena espiritual que se expresaba mediante el término griego «anatema» o mediante amenazas de excomunión.

Como señala Marc Drogin en su libro Anathema! Medieval Scribes and the History of Book Curses, una de las maldiciones más amenazantes de la Edad Media la encontramos en la llamada Biblia de Arnstein (c. 1172) ${ }^{8}$. En esta maldición se condena al ladrón de libros a una muerte por tortura, enfermedad y ejecución, curiosamente por ahorcamiento, como en el ejemplar estudiado.

Liber sancte Marie sancti que Nycolai in Arrinstein Quem si quis abstulerit Morte moriatur in sartagine coquatur caducus morbus instet eum et febres et rotatur et suspendatur Amen

Libro de [la abadía de] Santa María y San Nicolás en Arnstein. Si alguien lo roba: que sea muerto, sea asado en una sartén, contraiga la enfermedad [la epilepsia] y la fiebre lo ataque, y sea girado [en la rueda] y ahorcado. Amén (McKendrick y Doyle, 2007: 95).

\footnotetext{
${ }^{7}$ Hic liber est meus quem mihi dedit Deus (Este libro es mío, que Dios me lo dio), Hic liber est meus. Testis est Deus. Qui eum rapiat, diabolus capiat (Este libro es mío. Dios es testigo. Quien me lo robe lo lleve el diablo), Qui me furatur, mala morte moriatur (Quien me robe tenga una mala muerte), etc...

${ }^{8}$ Harley MS 2798, f. 235v. Disponible en British Library:

<http://www.bl.uk/manuscripts/FullDisplay.aspx?ref=Harley_MS_2798> [Consultado el 30-04-2019].
} 
Observamos un claro paralelismo entre este tipo de maldiciones bibliotecarias, las citadas fórmulas latinas y los ex libris tradicionales, que con la misma función de proteger el libro con amenazas coercitivas se han seguido utilizando en Europa e Hispanoamérica hasta la actualidad. Tanto las mencionadas amenazas medievales como los ex libris tradicionales atestiguan el gran valor material y espiritual que atribuían los propietarios a sus libros. La pérdida de un libro no solo significaba una pérdida material, sino que podía privar de manera permanente a una comunidad religiosa o a los propietarios particulares de un conocimiento esencial. Estos ex libris amenazantes eran un intento de preservar sus colecciones en el que subyace un evidente amor por los libros.

Otro ejemplo de este tipo de ex libris tradicionales que incluyen amenazas, con el íncipit «si este libro se perdiera...», que merece la pena dar a conocer, es el del ex libris incluido en un ejemplar del libro Demostración mecánica de las enfermedades que produce el uso de las cotillas, de D. Mariano Martínez Galinsoga ${ }^{9}$, que se encuentra en la Biblioteca Nacional de España.

Es para el uso de Bienvenido Frutos. Si este libro se perdiera como suele suceder, suplico a quien se lo ayara me lo supiera volver y si no me lo bolbiera, le daré de merendar cuatro palos en las costillas para que no lo aga más. Lo firmo Nicolasa Batine a 28 de Nobiembre del año de 1831.

En este tipo de ex libris, que A. L. Bouza denomina «fórmula clásica escolar» (Bouza, 1990, p. 21), el nombre del propietario del libro se puede presentar en ocasiones mediante fórmulas, como «pertenece a...», «es propiedad de...»o, como en los ejemplos descritos, «es para uso de...», etc., seguidas de un pequeño texto o poema que, guardando siempre los rasgos de su estructura primigenia, presentan infinidad de variantes y modificaciones.

Resulta llamativo que siendo estos textos fundamentalmente de transmisión escrita tengan rasgos estilísticos, modos de evolución y procesos de variación similares a los de transmisión oral. Los transmisores de estos ex libris, generalmente niños y estudiantes, tuvieron un papel activo y dinámico en su transformación sin limitarse a reproducirlos literalmente como si de simples copias escritas se tratara (véase Pedrosa, 2000: 132).

El siguiente ex libris de Miguel Hernández es un ejemplo paradigmático de este proceso de carácter creativo. El poeta escribió, estando en la cárcel entre marzo y septiembre de 1939, en la cubierta de su cuaderno manuscrito del Cancionero y romance de ausencias, «para uso del niño Miguel Hernández», y a la vuelta de la misma, este ex libris único y personal:

Si este libro se perdiera, como puede suceder, se ruega a quien se lo encuentre me lo sepa devolver.

Si quiere saber mi nombre aquí abajo lo pondré:

Con perdón suyo, me llamo

M. Hernández Gilabert.

${ }^{9}$ Disponible en la Biblioteca Digital Hispánica:

<http://bdh-rd.bne.es/viewer.vm?id=0000125832\&page=1 > [Consultado el 30-04-2019]. 
El domicilio en la cárcel.

Visitas de seis a seis (Hernández, 1984: 72-73).

En definitiva, las variantes que se aprecian entre las distintas versiones de estos ex libris tradicionales son señales de un tipo de transmisión que se asemeja, en su poética y en sus resultados, a la oral. Los ex libris tradicionales manuscritos son un repertorio en el que confluyen de manera ejemplar los rituales de la cultura escrita, los recursos poéticos de la oral y la vocación de variabilidad y de persistencia de la cultura popular.

\section{BIBLIOGRAFÍA}

Ansorena, José Luis (1999): «San Martín Eslava, Bonifacio», en Diccionario de la Música Española e Hispanoamericana, E. Casares (ed.), Madrid, Sociedad General de Autores y Editores, vol. 4, p. 759.

BouZA, Antonio Leandro (1990): El ex libris. Tratado general. Su historia en la Corona Española, Madrid, Patrimonio Nacional.

DOYLE, Kathleen y MCKENDRICK, Scot (2007): Bible Manuscripts: 1400 years of Scribes and Scripture, Londres, British Library.

Drogin, M. (1983): Anathema! Medieval Scribes and the History of Book Curses, Totowa, Allenheld \& Schram.

Gosálvez LARA, Carlos José (1995): La edición musical española hasta 1936, Madrid, Asociación Española de Documentación Musical.

HERNÁNDEZ, Miguel (1984): El hombre acecha. Cancionero y romancero de ausencias, (ed. de Leopoldo de Luis y Jorge Urrutia), Madrid, Cátedra.

IgLESIAS MARTíneZ, Nieves y LOZANO MARTíNEZ, Isabel (2008): La música del siglo XIX. Una herramienta para su descripción bibliográfica, Madrid, Biblioteca Nacional de España.

MCKENDRICK, Scot y DOYLE, Kathleen (2007): Bible Manuscripts: 1400 years of Scribes and Scripture, Londres, British Library.

MARTín ABAD, Julián (2004): Los libros impresos antiguos, Valladolid, Secretariado de Publicaciones e Intercambio Editorial, Universidad de Valladolid.

PedrosA, José Manuel (2000): “Si este libro se perdiera": geografía e historia de un ex-libris tradicional», Signo. Revista de Historia de la Cultura Escrita, 7, pp. 123134.

TúmBuRus, Juan (1912): Algo sobre los "ex-libris", Buenos Aires, Coni.

Fecha de recepción: 9 de marzo de 2017

Fecha de aceptación: 14 de mayo

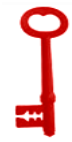

